\title{
Discussion of Extension and Mutation of Photography in Contemporary Art
}

\author{
Zhang Bochen ${ }^{1, a}$ \\ ${ }^{1}$ Shandong University of Arts, Jinan 250014, China \\ abochenart@126.com
}

\begin{abstract}
Keywords: photography; contemporary art; extension; mutation
Abstract. With the rapid development of science and technology, and promotion of digital technology, digital technology has been integrated to photography and has deeply promoted the changes of photography in art and contemporary society. More non-professional photography personnel adopt digital technology in art creation due to the strong expressive force and cheap use value of digital technology. Relying on the prominent expressiveness and objective characteristics, photography has attracted a large number of artists to involve in. The public involvement in creation makes the photography major to develop to multi-polarization direction and makes photography become an anastomosing thought thus to comply with development requirements of current era.
\end{abstract}

\section{Introduction}

The application of digital technology in photography has promoted the further development of photographic technology, added the elements and colors of modern photography, and further enhanced the photography quality. Traditional concept of photographic creation can hardly satisfy the development requirements of photographic creativity. It is required to promote the concept transformation of photographic creativity, and accelerate the extension and mutation of photography. Digital technology, as an important component of photography art, has become the inexhaustible motive force to propel the development of photography. The paper discussed the extension and mutation of photography in contemporary art.

\section{Extension of photography in contemporary art}

\subsection{Continuously expanding of photography group}

The rapid development of science and technology has provided energy and power for the development of digital technology, and has prompted great decreasing of photographic technology cost. More and more people adopt digital technology for photography, and can proficiently master the skills of photography. The reasons for presenting expanding development trend of photography group mainly include the following aspects: First of all, the development and popularization of the advanced photographic technology have promoted the competitiveness of the market. Some merchants will occupy the market advantages by reducing the price. The declining of market value has provided channels for more people to participate in photography. Secondly, the development of digital technology will prompt the use difficulty decreasing of the camera. The photography operation function is simple and will not cause limitation for photography crowd thus to provide technological base for photography staff. Thirdly, people have transformed from pursuing material life to spiritual life. Photography can satisfy people's pursuit of spiritual life. To record the lift by using photography is an essential method for people to enjoy happy life. It has laid the ideological basis for expanding the photography group [1].

Table 1 Reason for photography group expanding

\begin{tabular}{ll}
\hline & Reasons for photography group expanding \\
\hline 1 & Cheap camera price \\
2 & Camera using difficulty decreasing \\
\hline
\end{tabular}


Table 2 Digital technology provides foundation for photography group

\begin{tabular}{ll}
\hline & $\begin{array}{c}\text { Digital technology provides foundation for photography } \\
\text { group }\end{array}$ \\
\hline 1 & Economic foundation \\
2 & Technological foundation \\
\hline
\end{tabular}

The expansion of photography group is an inevitable trend of the current society. It has promoted the development of photography industry and caused many aspects influence on contemporary art. The expansion of photography group has provided an expression channel for the development of contemporary art, created more development direction and conformed to the pursuit of spiritual life of modern people. With the rapid development of social economy, material pursuing can hardly satisfy people's demands, and can develop spiritual pursuit gradually. Photography is the important manifestation for spirit pursuing. In addition, with the development of social economy, people will face large pressure in the life. Photography plays an important role on counseling people's pressure. Photography has strong flexibility and literariness characteristics. Photography can ensure comfort of body and health. In addition, there are a large part of photographers devoted in photography, and decisively abandoned the existing stable work thus to provide power for the development of photographic art, create wider development space and expand the development channel for photographic art. The performance carrier and channel of photographic art are more perfect with more artistic color [2].

Table 3 Impact of photography group expansion on contemporary art

\begin{tabular}{ll}
\hline & Impact of photography group expansion on contemporary art \\
\hline 1 & Artistic expression channel has been expanded \\
3 & Provide more development direction for arts \\
4 & Meet the demands of people's spiritual life \\
5 & Health and ease \\
6 & Provide developmental force for contemporary art \\
7 & Create development space for contemporary art \\
8 & Improve the photography art carrier \\
\hline
\end{tabular}

2.2 Continuous development of photographic technology

Photographic technology is the outcome of science and technology, including strong sci-tech elements. The development of photography technology has been greatly influenced by technical level constraints. Scientific and technical level will directly influence the development and improvement of photographic technology. It is required to constantly promote the development of science and technology thus to drive photography technology progress. In recent years, digital technology has been developing rapidly and has been extensively applied in photographic technology. The application of digital technology in photographic technology is based on computer. Computer plays important roles in computer processing data. In addition, during the application process of computer technology, decryption technology and encryption technique processing capacity have been enhanced. Information security has been ensured to certain degree. While adopting digital technique for photography, people can feel the strong stability of digital technology. In addition, as being significantly impacted by external factors, the information can be stored effectively for long term, and can cause greater convenience for photo storage.

The application of digital technology in photography technology, comparing with traditional photography, photographic quality is clearer. The image quality effects are better which can satisfy high quality requirements of modern personnel on picture. The traditional radiography technology is incomparable to photographic technology of digital technique. Combining with the actual situation of the physical material, background, color and light are subject to continuous adjustment so that the photos can satisfy people's demands, and can further improve photographic quality. Traditional photos are mainly presented in the form of paper which is adverse to long-term storage. The photos 
may show fuzziness and yellowing etc.. However, there are many storage channels for digital photos. Comparing to traditional photos, the photos can be stored in electronic method and can upload the photos to the Internet terminal so that the photography communication media is more diversified. It has promoted the diversification of contemporary art form, expanded photography group and promoted the effective succession of contemporary art.

Table 4 Impact of digital technique on photographic technology

\begin{tabular}{ll}
\hline & Impact of digital technique on photographic technology \\
\hline 1 & Photo quality and definition improvement \\
3 & Impact on audience visual \\
4 & Photo quality has been improved \\
5 & Photography medium media is more diversified \\
6 & More photo saving channels \\
7 & The photos can be stored for long term. \\
8 & Expanded photography group \\
\hline
\end{tabular}

\section{Mutation of photography in contemporary art}

With the popularity of the camera, it has promoted the rapid development of photographic art. In traditional photography, the photography works have been evaluated. It mainly pursues objective definition and can record the existing objective fact. In recent years, people have changed the concept on photography with the rapid development of photography technology, focusing on integrating the subjective thought to photography. In case of stricter requirements on abstraction and ambiguity of photography works, it has provided imaginary space for audience so that the audience has felt subjective thought of the photographer. In addition, documentary photography is the important manifestation for photography concept mutation. It is known as the highest expression of photographic art. It is the manifestation and expression of performance and idea. It is the representative reflection of real events [3].

Table 5 Reason for photography conception transformation

\begin{tabular}{ll}
\hline & Reason for photography conception transformation \\
\hline 1 & Improvement of popularizing rate \\
2 & Transformation of photography conception \\
3 & High requirements of audience on photography imaginary \\
4 & space an abstraction and vagueness of \\
5 & High requirements on abraphy works \\
6 & Demands on documentary photography \\
\hline
\end{tabular}

\section{Conclusions}

Photography is an important part of the current era of artistic expression. For better development, photography needs to get adapt to the spiritual life, as well as science and technology. It is required to combine with current development of current era, continuously broaden artistic expression channel, improve artistic expression, update photography art concept and promote the favorable development of photographic art.

\section{References:}

[1]Den Dunnen J T, Antonarakis S E. Mutation Nomenclature Extensions and Suggestions to Describe Complex Mutations: A Discussion[J]. Human Mutation, 2000, 15(1):7-12. 
[2]Wang H J, Lian X J, Guo K L, et al. Photostability Discussion on Method of Determination of Monascus Pigments Powder[J]. Acta Universitatis Medictnae Tangji, 2005, 34(4):472-474.

[3]Mchenry C R, Mehta R, Wilhelm S, et al. Nodule size is an independent predictor of malignancy in mutation-negative nodules with follicular lesion of undetermined significance cytology DISCUSSION[J]. 2013, 154(4):736-738. 